\title{
Ensinando geografia para alunos surdos e ouvintes: algumas adaptações na prática pedagógica
}

\author{
Geografia estudiantes de enseñanza para sordos y oyentes: \\ algunos ajustes en la práctica educativa
}

\section{Teaching geography for deaf and hearing students: some adjustments in the practice of teaching}

\author{
Ricardo Lopes Fonseca \\ ricardolopesfonseca@hotmail.com \\ Universidade Estadual De Londrina \\ Eloiza Cristiane Torres \\ elotorres@uel.br \\ Universidade Estadual de Londrina
}

Resumo: Este estudo engloba as principais características sobre a educação inclusiva do aluno surdo nas salas de aulas, bem como os resultados coletados durante o processo da confecção da dissertação sobre esse tema. São várias as reflexões que se apresentam no transcorrer deste trabalho. A expectativa é que o estudo aqui exposto seja de fácil compreensão para o leitor e que consiga despertar a consciência e o senso crítico com referência à situação do modelo de inclusão de alunos surdos nas escolas públicas do Brasil. Considera-se educação inclusiva o método de inclusão de distúrbios de aprendizagem na rede básica de ensino. Essa discussão é direcionada para a variedade de implicações sobre o ensino de Geografia para os alunos surdos, que deve ser visto com muita atenção, pois, embora as propostas pedagógicas direcionadas para esses alunos tenham como finalidade possibilitar o crescimento total de suas capacidades, constata-se que não é isso o que ocorre nas salas de aulas. O objetivo geral deste estudo é aplicar várias metodologias para o ensino de Geografia em salas de aula com alunos surdos e ouvintes a fim de averiguar a validade de cada uma das possibilidades pedagógicas usadas, ou seja, se é possível seu aproveitamento em sala de aula com os dois grupos de alunos.

Palavras-chave: Geografia. Surdez. Ensino. Práticas pedagógicas.

Resumen: Este estudio abarca las principales características de la educación inclusiva de los estudiantes sordos en las aulas, así como los resultados obtenidos durante el proceso de preparación de la tesis doctoral sobre este tema. Hay varias consideraciones que surgen en el curso de este trabajo. La expectativa es que los pensamientos se mencionan aquí son fáciles de entender para el lector y son capaces de aumentar la conciencia y el sentido crítico en relación con la situación del modelo de inclusión de estudiantes sordos en las escuelas públicas de Brasil. Se considera el método de la educación inclusiva como trastornos de aprendizaje en la educación primaria. Esta discusión está dirigida a una variedad de consecuencias para la geografía de enseñanza 
para los estudiantes sordos, porque la educación para los estudiantes sordos debe considerarse con sumo cuidado, ya que las propuestas pedagógicas dirigidas a las personas sordas tienen por objeto permitir el crecimiento total sus capacidades, sin embargo, lo que vemos es que esto no es lo que sucede en las aulas. El objetivo de este estudio consiste en aplicar diversas metodologías para la enseñanza de la Geografía en las aulas con los estudiantes sordos y oyentes, con objeto de comprobar la validez de cada una de las posibilidades pedagógicas aplicadas, es decir, si es posible su uso en salón con dos grupos de estudiantes.

Palabras clave: Geografía. Sordera. Educación. Prácticas Pedagógicas.

\begin{abstract}
This study deals with the main characteristics of the inclusive education for deaf students in the classroom, as well as the results collected during the process of preparing a dissertation on this topic. Several considerations are shown through this essay. The conducted study is expected to be of easy understanding for the reader and to be able of raising the awareness and critical thinking about the model of inclusion of deaf students in Brazilian public schools. Inclusive education is considered to be the method of inclusion of learning disorders in elementary and high education, here directed to the variety of implications about teaching Geography for deaf students. The education for deaf students should be carefully observed, since the proposals directed to this group have the goal of enabling the total development of their capacity. However, this is not what happens in classrooms. This essay aims to apply a variety of methodologies for Geography teaching in classrooms with deaf and hearing students, in order to investigate the importance of each pedagogical possibility applied, and check if it is possible to use them in classroom with both groups of students.
\end{abstract}

Keywords: Geography. Deafness. Education. Pedagogical practices.

\title{
INTRODUÇÃO
}

O estudo da Geografia deve ter uma expectativa devidamente envolvida com a realização da cidadania. É preciso preparar o aluno para a vida e não somente para criar conceitos ou desenvolver a concorrência no universo do trabalho.

Existem várias linguagens pedagógicas que são alinhadas com o ensino de Geografia e que podem ser adequadas à inclusão dos alunos surdos. Para tanto, foram realizadas entrevistas com os professores de Geografia e foram selecionadas as práticas pedagógicas mais citadas por eles para serem aplicadas em sala de aula. Foi elaborado um projeto de intervenção pedagógica em que o pesquisador apresentava os materiais referentes a uma dada metodologia, e que esta fosse compatível com o conteúdo que o docente da sala estivesse trabalhando com seus alunos, com a finalidade de saber se o uso dessa ferramenta era valida para ensinar os alunos surdos e ouvintes sem prejuízo para nenhuma das partes.

As aplicações ocorreram em diversas escolas de alguns municípios da região Norte do Paraná, onde há pelo menos um aluno surdo estudando junto com alunos ouvintes. Foram aplicadas três vezes cada ferramenta de ensino, independentemente do conteúdo que estava sendo ministrado no momento. 


\section{DA VALIDADE DOS INSTRUMENTOS DE ENSINO}

Neste trabalho, é apresentada a discussão relacionada às metodologias aplicadas nas salas de aulas de diversas escolas. Para proteger a imagem dos entrevistados, não são divulgados, os seus nomes nem os dos envolvidos nos questionários aplicados. Leva-se em consideração, ainda, a vivência dos entrevistados quando os mesmos já presenciaram o uso desses métodos de ensino.

Outro fator que se faz importante destacar está relacionado às turmas selecionadas. Os métodos foram aplicados em séries/anos diferentes, com a finalidade de verificar o aspecto comportamental dos alunos em relação à metodologia, uma vez que pode haver variação de interesse pelo método de acordo com a idade e/ou série/ano. Cada prática pedagógica apresentada foi aplicada três vezes em escolas diferentes.

Quando o professor organiza em sala de aula um tipo de recurso diferente das metodologias tradicionais experimentadas, isto é, um modelo diferenciado para motivar os alunos para a compreensão do conteúdo das aulas, nota-se que os alunos são estimulados e ficam mais interessados nesse modelo de aula, especialmente pela curiosidade.

Assim, quando o professor utiliza recursos diferenciados como instrumentos de ensino, os alunos manifestam, espontaneamente, o interesse por esse tipo de aula, e a aceitação e participação acontecem de maneira totalmente satisfatória. As reflexões referentes às metodologias de ensino de Geografia têm dado ênfase à necessidade de a escola fornecer ao aluno uma aprendizagem na leitura e escrita de forma crítica, ou seja, de maneira a ajudar os educandos na edificação do senso crítico.

Na prática, isso significa que o aluno deve estar apto para as seguintes atividades: separa o que é teoria daquilo que é experiência; elaborar problemas a serem solucionados; realizar estudos e pesquisas; identificar diferentes valores tácitos relacionados às suas tomadas de decisão; e avaliar as inúmeras visões que se apresentam.

Para Callai (2001, p. 133):

[...] inúmeros autores têm se dedicado a pensar o significado da Geografia no ensino, em todos os níveis. Para alguns, o conteúdo da Geografia é o mundo, o espaço e sua dinâmica contínua, onde as mudanças ganham cada vez mais velocidade. Nesse contexto, é preciso dar condições aos alunos de pensar e agir, buscando elementos que permitam compreender e explicar o mundo em permanente reinvenção.

A Geografia, por sua própria lógica de conhecimento, caracteriza-se pelas relações entre fenômenos físicos e humanos, ou entre a sociedade e a natureza, e também presta sua contribuição na escola para a realização da interdisciplinaridade, confirmando sua exclusividade, ou seja, que ela própria se forma a partir de grande variedade de temas, conservando sempre o espaço geográfico como eixo principal.

É essencial que em salas de aulas frequentadas por alunos surdos e ouvintes haja métodos de ensino que diminuam as dificuldades de aprendizagem, facilitando o acesso aos dois grupos. 
Casseti (2002, p. 152), afirma que “[...] cabe à Geografia a função de preparar o aluno para uma leitura da produção social do espaço, repleto de contradições, ou o desvendamento da realidade, negando a 'naturalidade' dos fenômenos que imprimem certa passividade aos indivíduos". É válido ressaltar que essa melhor qualidade no ensino deve atingir os dois grupos de alunos, isto é, que alunos surdos e ouvintes entendam o mesmo conteúdo aplicado com os mesmos métodos pedagógicos. É importante reforçar o papel do intérprete (a pessoa que vai passar as informações aos alunos surdos), o qual acompanhar as aulas em razão da importância das traduções, sendo que ele não poderá desabonar o método adotado pelo professor e assim facilitar o seu próprio trabalho.

\section{ATIVIDADES LÚDICAS}

Toda pessoa pode beneficiar-se de atividades lúdicas, tanto como diversão e prazer quanto como aprendizagem. Diversas capacidades podem ser estimuladas por meio de atividades lúdicas, bastando para isso saber explorar a realidade e refletir sobre ela, explorar a cultura na qual se vive, participando e também discutindo regras e funções sociais. Nas atividades lúdicas a realidade pode ser superada através da imaginação.

As atividades lúdicas ajudam na criação de uma satisfação sobre o assunto a ser trabalhado e objetivam estimular os alunos a se expressar, a agir e interagir nas práticas lúdicas organizadas na sala de aula.

De acordo com alguns alunos surdos, é importante haver "diversidade de jogos", com uma variedade de opções que, ao serem selecionadas, podem viabilizar um melhor aprendizado. Para eles, é importante também em alguns momentos "deixar os jogos mais lentos", pois os alunos surdos recebem as informações pertinentes ao conteúdo através do intérprete; se o jogo exigir rapidez por parte dos envolvidos, o aluno surdo pode ser prejudicado, pois, até o tradutor enviar as informações através da Libras, o aluno pode já ter perdido sua vez de jogar.

Quanto aos alunos ouvintes, mesmo havendo uma evidente vantagem auditiva sobre os alunos surdos, para alguns deles há a necessidade de "variações de atividades", pois o uso de repetidas atividades faz com que eles se sintam entediados.

Para os intérpretes entrevistados, alguns pontos precisam ser melhorados nesse método, devendo ser aplicado "com mais dinâmica, sem ser acelerado", "buscar maior organização para que seja possível todos os alunos participarem" e "dar suporte para que isso aconteça". Agindo dessa forma os intérpretes acreditam que a prática dessa metodologia pode ser otimizada.

Quanto aos professores de Geografia, eles acreditam que deve ser melhorada a "aplicação de diferentes atividades" e "a abordagem dos conteúdos", pois, direcionando a atividade mais apropriada para cada conteúdo específico, através da forma como o professor trabalha cada conteúdo, os resultados serão cada vez melhores. 
As atividades lúdicas devem ser sempre dinâmicas, nem muito rápidas nem demoradas; o educador tem que estar atento aos limites cognitivos de cada educando, e cabe ao professor, também, estabelecer a ordem na sala de aula.

\section{CHARGES, TIRAS E QUADRINHOS}

As revistas em quadrinhos são, costumeiramente, as primeiras leituras das crianças e continuam presentes na vida de muitos adultos. É perceptível o aumento do uso de tiras de quadrinhos, charges, cartuns no meio escolar, como também em muitas provas de processo de seleção, sabendo-se ainda que esse tipo de abordagem é parte rotineira de quase todas as pessoas, sendo amplamente divulgado pelos meios de comunicação. Por ser uma leitura apreciável, cativante e prazerosa para a maioria dos alunos, esse tipo de atividade pode ser um fator facilitador para organizar uma discussão com certo rigor científico, a partir de componentes do cotidiano.

Em relação aos alunos surdos, eles acreditam que o recurso é excelente, com exceção de um entrevistado, o qual classificou o método como bom; para ele o que precisa ser melhorado são as "variedades de material para um mesmo tema", pois é importante ter sempre quantidades significativas de informações sobre um conteúdo, e não determinar o número exato de informações para esse tipo de metodologia.

Quanto aos alunos ouvintes, as opiniões são praticamente as mesmas dos surdos, tanto em relação ao que precisa ser melhorado, quanto ao que eles não gostam nesse tipo de método; para um aluno é preciso que haja "variedades de personagens" para melhorar a aula. Enquanto para outros "é necessário haver maior quantidade de materiais" e que, também, estes "sejam mais populares", a fim de despertar um interesse maior pela aula.

De acordo com os intérpretes entrevistados, é importante que seja melhorada a "abordagem metodológica", e que sejam utilizados "personagens mais conhecidos pelo público-alvo". Eles consideram que essas são duas atitudes que melhoram qualitativamente a prática do recurso.

As opiniões dos professores foram as mais diversas; para um é necessário que haja "variedade de charges e tiras", enquanto para outro "é importante que sejam mostradas aos alunos as tiras de personagens mais conhecidos, pois isso motiva o interesse" e para outro educador "é preciso mudar a forma como é levado o debate acerca do conteúdo". Essas três opiniões demonstram o quanto, em alguns casos, precisa ser aperfeiçoado o uso desse recurso, cuja finalidade é desenvolver no aluno o raciocínio crítico e interpretativo de cada material.

\section{DESENHOS}

As primeiras relações que o aluno organiza e utiliza são simples, chamadas topológicas, como por exemplo: vizinhança, separação, ordem, envolvimento e continuidade. Essas ligações possibilitam à criança discernir figuras abertas e fechadas, embora não possibilite que ela consiga distinguir um círculo de um quadrado. 
Para os alunos surdos, algumas mudanças precisam ocorrer, com a finalidade de melhorar essa prática pedagógica. "O objetivo de se fazer o desenho", "a escolha do que será desenhado" e "juntar o conteúdo com o desenho" foram as respostas dadas nas entrevistas sobre essa questão. Como se pode notar, principalmente a partir da ultima opinião, que demonstra- que os estudantes não compreendem a importância dessa atividade para sua aprendizagem, compete ao professor trabalhar detalhadamente o uso desse recurso.

Para os alunos ouvintes, as opiniões não são tão diferentes das dos alunos surdos. Quando questionados sobre o que deve ser melhorado nessa metodologia, a primeira resposta foi um tanto parecida com uma resposta de um aluno surdo: "o objetivo pelo qual tem que ser desenhado", porque muitas vezes esse objetivo não está claro para eles; portanto o professor sempre deve expor para seus alunos qual a finalidade do trabalho; para um outro estudante deve ser melhorada "a técnica do desenho". É importante ressaltar que o professor deve deixar o educando escolher a forma como estará realizando esse trabalho, pois o professor poderá encontrar uma agradável surpresa ao verificar os resultados desse método.

Para os intérpretes, a relação com esse método se dá em duas etapas: a primeira tem a ver com a questão de melhorias a serem realizadas na metodologia: "as interações entre conteúdo e o objetivo do desenho", em que o professor sempre deverá fazer as ligações necessárias entre teoria e prática; "a forma como o professor pede o desenho", num sentido de evidenciar o objetivo e o destino do desenho, devendo estar sempre claro para os educandos; e "o objetivo pelo qual o aluno realiza essa atividade", o que demonstra que muitas vezes os alunos não sabem por qual razão precisam realizar esse exercício.

Os professores também possuem opiniões semelhantes às dos intérpretes, tanto na questão do que precisa ser melhorado como na da forma como se deve trabalhar esse recurso. De acordo com os docentes entrevistados, as respostas para a primeira questão são: "correlação da atividade com o conteúdo apropriado", "interagir conteúdo com o método", e "abordagem do conteúdo"; percebe-se que os professores estão atentos à forma como se trabalha o conteúdo e o exercício. As opiniões para a segunda pergunta foram: "sempre instigar no aluno seu lado de criação atrelado ao aprendizado", "estimulando no aluno a ação de reconhecimento do espaço desenhado" e "estimulando a ação criativa do aluno"; aqui se percebe que os professores estão de certo modo preocupados com o aprendizado do aluno e estão atentos aos sentimentos que os educandos revelam no decorrer do trabalho acerca do ambiente onde vivem.

\section{FILMES E VÍDEOS}

O cinema pode ser mais útil na sala de aula, na forma de documentários ou curta-metragens de ficção. Os documentários devem ser analisados, assistidos e discutidos durante o tempo de uma aula. Não é certo usar duas ou três aulas em dias diferentes para assistir a um filme e só na outra semana debatê-lo. Dessa maneira, quando um filme for 
passado, o professor deve recortar os trechos mais adequados para discutir em sala de aula.

Os alunos surdos apontam algumas sugestões para a melhoria dessa metodologia: trata-se primeiramente de uma "relação mais clara com o conteúdo", de forma que o aluno consiga assimilar as ideias mais facilmente, através de um debate que o professor faça no decorrer do material apresentado. Outra sugestão é "atualizar os vídeos", assim o professor não corre o risco, dependendo do conteúdo, de apresentar um material já ultrapassado.

Os alunos ouvintes também necessitam que os professores utilizem "vídeos mais recentes"; vídeos atualizados que tragam a mensagem na linguagem do aluno facilita o entendimento do conteúdo.

De acordo com os tradutores é importante que os professores trabalhem com essa metodologia "por trechos pausados", "sempre com legendas", e tentem trazer para "a vivência dos alunos". Dessa forma os intérpretes acreditam que o recurso dos filmes e vídeos podem ser de grande valia para o aprendizado dos estudantes.

Os professores de Geografia entrevistados acreditam que para aperfeiçoar o uso desse recurso é preciso "focar no conteúdo da aula, às vezes dispersa", e trazer para essas aulas "vídeos atuais". Com isso os resultados encontrados estarão dentro das expectativas esperadas, tanto pelos professores quanto pelos alunos.

\section{GLOBO TERRESTRE}

Um globo deveria estar presente no momento de serem pesquisados assuntos como orientação e localização, para esclarecer as coordenadas geográficas, criando base de noções quanto à posição da Terra no espaço e suas relações no sistema solar, e assim afastar as dificuldades para a compreensão das divergências quanto à projeção da Terra sobre um mapa e para explicar a ligação entre a forma da Terra e a variedade ambiental, especificamente o fator clima. A utilização correta do globo contribui enormemente para o aluno desenvolver o entendimento da universalidade e para promover condutas de respeito aos povos, consideração, aceitação, cooperação, na medida em que a configuração do mundo é vista como um todo e não de maneira dividida.

Para os alunos surdos, as sugestões acerca desse material estão ligadas à quantidade de objetos disponíveis: "a quantidade de globo", "mais globos" e "número de globos por grupos de colegas"; aqui o globo é visto como um material que deve ser manuseado pelos alunos e não apenas apresentado formalmente, sendo importante a escola contar com um número maior de globos.

Quanto às opiniões dos alunos ouvintes, as repostas sobre o que precisa ser melhorado se resumem basicamente em duas: "haver mais globos" e "tamanho do globo", alguns conteúdos exigem que os globos sejam de tamanho maior ou menor, outros conteúdos trazem a necessidade de cada aluno, ou grupos reduzidos, possuir um globo para manuseio. 
As opiniões dos intérpretes também estão relacionadas à quantidade de objetos na escola: "disponibilização de materiais" e "quantidade de material", o que evidenciam que algumas escolas não contam sequer com um único globo, como retrata a primeira opinião.

As respostas dos docentes foram as mais diversificadas nesse grupo de entrevistas. Primeiramente, quando questionados a respeito das melhorias necessárias para o uso do método, as respostas foram: "a forma de aplicação do método", "a escala do globo" e "quantidade de materiais"; a primeira opinião mostra que esse professor se preocupa com a abordagem dessa metodologia, mas também revela que o método não está sendo eficaz e exige melhorias na forma como cada educador trabalha em sala de aula com ele; em relação a segunda resposta percebe-se que alguns globos, de baixa qualidade, não apresentam escala; e o terceiro professor entrevistado diz que a quantidade de globos é inferior à necessária.

\section{GRÁFICOS, TABELAS E QUADROS}

As reproduções gráficas, especificamente gráficos, tabelas e quadros, são componentes essenciais na resolução de assuntos geográficos, embora, em algumas situações, constituem-se obstáculos à aprendizagem, causados pelas dificuldades que os alunos enfrentam ao lidar com esses instrumentos.

Os alunos surdos entendem que, se fossem realizadas algumas melhorias no uso dessa prática, tornaria melhor a leitura das informações apresentadas. Suas respostas foram: "tipo de gráficos" e "menos informações por quadros e tabelas", uma vez que os professores adaptam as informações através de gráficos apropriados, cujas informações poderiam ser mais bem trabalhadas.

Os alunos ouvintes também acreditam que alguns pontos precisam ser adequados em relação ao uso desse método: "qualidade dos gráficos", "formato dos gráficos" e "menos informações nas tabelas" são algumas posturas às quais os educadores precisam prestar atenção ao utilizar essa fonte.

Os intérpretes avaliam o uso desse material, em primeiro lugar, sob o ponto de vista das melhorias necessárias: "menos informações nos quadros e tabelas", "abordagem do método" e "objetivo do uso deste recurso"; essas opiniões demonstram alguns detalhes que os professores precisam corrigir e/ou adequar para que o aluno possa fazer melhor uso do recurso. Os educadores entrevistados demonstraram que também estão atentos às melhorias que devem ocorrer no uso desse recurso: "diversidade de formas dos gráficos" e "aplicação do material sempre com coerência do conteúdo". Essas respostas evidenciam que os professores já sabem o que deve ser feito para melhorar o uso do recurso.

\section{IMAGENS E FOTOS}

O ensino de Geografia mostra uma obrigatoriedade crescente de debater caminhos que levem o aluno a se envolver com o mundo à sua volta, encerrando a simples 
descrição de paisagens. A aplicação de gravuras, fotos, desenhos e outras representações em sala de aula proporcionam ao aluno o aumento de sua habilidade na observação e valorização do que existe à sua volta. Para os alunos surdos, alguns pontos precisam ser aperfeiçoados, entre eles: "qualidade e quantidade das fotos". Nesse ponto, compete ao professor verificar a qualidade das imagens, de modo que não interfira na aprendizagem dos alunos; quanto à questão de quantidade, isso pode variar de acordo com o objetivo das aulas, bem como a viabilização de imagens apropriadas para o conteúdo.

Os alunos ouvintes, assim como os estudantes surdos, consideram esse recurso um bom meio para as aulas de Geografia, mas acreditam que algumas ponderações sobre seu uso são necessárias. Um dos alunos entrevistados sugere que as "imagens devem ser mais adequadas às aulas", o que pode indicar ao professor que ele deve levar para a sala de aula uma variedade de fotos que expressem da melhor forma possível o conteúdo ministrado.

Os tradutores consideram, em linhas gerais, que é importante os professores estarem atentos à "qualidade e abordagem desse recurso", pois, de acordo com os intérpretes, em determinados momentos o educador foge da aula pelo mau uso do método.

Os professores fazem uma autoavaliação da forma como estão efetivando o uso desse recurso. De acordo com eles precisa ser trabalhada em sala de aula a utilização de imagens da seguinte forma: "com o máximo possível de imagens que se referem aos conteúdos", "na forma de debate atrelado ao conteúdo", e "sempre abordando de forma direta e clara e com a participação dos alunos"; dessa forma o docente está incentivando o raciocínio crítico em seus alunos, através de análises em grupos no decorrer de suas aulas. Modificando de modo positivo o uso desse recurso, os educadores promovem um aperfeiçoamento no ensino de Geografia.

\section{INTERNET E COMPUTADORES}

A internet pode exercer um papel muito importante, ao auxiliar o professor na interligação do aluno com essas novas tecnologias, e a própria internet ao conteúdo de sua aula.

Para os alunos surdos, algumas posturas precisam ser corrigidas quanto ao uso desse recurso, como por exemplo: a "organização da sala de informática", pois muitas vezes os alunos encontram-se eufóricos, daí a importância de o professor ter domínio de seus alunos; "ter um computador para cada aluno", aqui estão em questão a organização da escola e o tamanho da sala de informática; nesse caso, o professor deverá adequar suas atividades à quantidade de computadores e dividir os alunos em duplas; e o acesso a "sites mais conhecidos", o que implica uma melhor aceitação por parte dos alunos, mas não que o professor não possa apresentar outras páginas que possam fazer os alunos se interessarem.

Os alunos ouvintes também possuem opinião acerca dessa metodologia muito semelhante à do grupo anterior, com exceção de uma colocação de um aluno acerca das 
melhorias necessárias, pois para ele muitos sites não possuem "informações com credibilidade", o que prejudica um melhor aprendizado.

Os tradutores opinam sobre o modo como os professores devem trabalhar esse recurso: "de forma lúdica", "tratar com importância o uso desse recurso", e "sempre de forma dinâmica, com acesso a sites de atividades lúdicas voltadas aos conteúdos específicos"; são atitudes como esssas que farão o educador atingir os objetivos de suas aulas.

Os educadores acreditam que alguns pontos necessitam ser corrigidos para trazer aos alunos um melhor aproveitamento da informática na escola: "atendimento individual aos alunos" e "otimização do tempo na sala de informática", principalmente em relação à questão de atender os alunos individualmente, o que pode contribuir para um melhor resultado da aula, pois muitos alunos da rede pública de ensino não possuem noções de informática e ficam mais atrasados, em relação aos demais.

\section{JORNAIS E REVISTAS}

Utilizando o jornal ou a revista como um subsídio ao ensino, o professor pode provocar uma aproximação entre o conteúdo desenvolvido em sala de aula e as matérias das reportagens informadas pela mídia, ligadas ao cotidiano do aluno, para que assim ele possa vislumbrar as modificações que estão acontecendo no mundo e no seu próprio país.

Os alunos surdos enxergam a necessidade de utilizar "jornais mais conhecidos", bem como revistas de maior circulação, o que pode evidenciar o fato de esses materiais trazerem informações sobre vários lugares do mundo.

Os estudantes ouvintes apresentaram respostas semelhantes às dos alunos surdos para as duas mesmas perguntas (O que precisa ser melhorado?, e O que você não gosta neste tipo de método?), e as respostas foram: "apresentar matérias de jornais de maior circulação" e "o uso do sensacionalismo".

Os tradutores argumentam que determinadas atitudes precisam ser corrigidas, no que diz respeito a "manchetes e reportagens mais voltadas para o conteúdo", "a variedade de jornais e revistas", e "a linguagem transmitida ao aluno", são posturas displicentes do docente que precisam ser corrigidas para otimizar o uso desse recurso em sala. Os professores de Geografia acreditam que determinadas posturas podem contribuir para uma melhora significativa da aprendizagem dos educandos através desse método: "o dialogo e a forma de abordagem", "melhor uso dos materiais", "a forma como se apresenta ao aluno a temática através do método"; com essas correções o educador estará promovendo um melhor ensino a seus alunos.

\section{LITERATURA}

A literatura pode e deve ser usada pelos geógrafos no desenvolvimento de ensino/ aprendizagem, especialmente as obras literárias regionalistas, que ao serem estudadas, pos- 
sibilitam um melhor entendimento da produção do espaço regional no processo histórico no âmbito nacional.

Um dado muito significativo no processo de ensino/aprendizagem que precisa ser estimulado desde o princípio da alfabetização é a valorização da leitura. $O$ aluno se sente muito mais entusiasmado e interessado em conhecer uma obra literária romanesca do que ler um livro didático com termos técnicos complexos. Isso não significa afirmar que seja dispensável a leitura de textos didáticos e a aprendizagem de termos técnicos da disciplina, porém, este aprendizado pode ser adquirido de outras formas, como por exemplo, principiando com debates do assunto em sala de aula direcionados pelo romance literário.

Na relação entre Geografia e literatura, os textos literários apresentam-se como um rico material a ser apreciado pelos geógrafos, pois eles evocam a alma dos lugares e o cotidiano das pessoas.

A partir dessa relação é possível perceber uma boa aceitação por parte dos alunos surdos no uso desse recurso; de acordo com apenas um entrevistado deveria ser melhorada a questão da "escolha dos livros", pois, dependendo da obra, o aluno pode ou não se interessar.

Trazendo a literatura para uma abordagem mais atual, isso certamente despertará um olhar diferente no aluno, do que utilizar um livro mais antigo, "livros que não chamam atenção", "livros de modismos, de modinha", e "livros com linguagem difícil"; esses são aspectos que os alunos ouvintes apontam como negativos no uso dessa metodologia.

"Atualização de livros", "exploração do recurso" e "escolha das obras" são as opiniões dos intérpretes acerca do que precisa ser melhorado no uso dessa prática de ensino, cujas respostas indicam o desejo deles de que os alunos obtenham um melhor resultado nos ensinos.

Para haver melhorias substanciais no uso desse material os docentes precisam desenvolver essa metodologia através da "escolha de alguns trechos para debate", "estimulando a leitura" e "motivando a leitura através de alguns pontos". De modo que o educador esteja atento às dificuldades que cada aluno possui de leitura e compreensão de uma obra.

\section{MAPAS E ATLAS}

Ao se mencionar a palavra mapa, imediatamente a ligamos à Geografia. É uma característica por excelência cultural.

Nas aulas de Geografia o assunto de Cartografia e linguagem Cartográfica pode ser ensinado e entendido, e não somente esporadicamente comentado. Hoje é primordial que os alunos conheçam o mapa e consigam desenvolver uma leitura dele, identificando o que está ali e isso acontecendo, possam entender a realidade.

Um comentário realizado por um aluno surdo está relacionado à "atualização do atlas", como se nota que, ao menos, um estudante está atento à transformação de alguns 
territórios, logo o docente precisa estar atento a esse detalhe e exigir da escola sempre uma renovação de seus atlas.

Em relação às opiniões no sentido de melhorias nessa metodologia os alunos ouvintes acreditam que não há necessidade de mudar o modo como seus respectivos professores abordam os conteúdos com esse recurso.

Os tradutores afirmam que, para se trabalhar essa metodologia, algumas posturas precisam ser adequadas, tais como: "dependendo da finalidade do conteúdo, com comparações de mapas", "de forma lúdica como meio para auxiliar os alunos na orientação” e "avaliar mapas de diversos períodos".

Os professores de Geografia, de modo geral, afirmam que é necessário o docente "ter acesso a coleções de mapas" e "utilizar mapas atualizados" como forma de melhorar o uso dessa técnica de ensino.

\section{MAQUETES}

Quando as aulas são organizadas com a ajuda de maquetes, a apreensão e a identificação dos objetos, como também os esclarecimentos dos conteúdos, são mais bem aproveitados, possibilitando o surgimento de uma série de dúvidas e interesses voltados para os componentes presentes nas maquetes.

Os alunos surdos acreditam que os professores precisam estar atentos a dois detalhes para tornar o uso desse método mais eficaz: "tipo de maquete" e "o uso final da maquete"; este último comentário mostra a preocupação do aluno com o que será feito com a maquete, que muitas vezes fica exposta alguns dias na escola e depois vai para o lixo, o que faz com que os estudantes sintam-se menos motivados a realizar esse tipo de trabalho por acharem que seu trabalho, ao ser descartado, foi desvalorizado.

Os estudantes ouvintes dizem gostar de realizar esses trabalhos e não apontam nenhuma melhoria a ser realizada. Entretanto, apontam fatos que nos dão a noção de sentimentos negativos, principalmente, quando afirmam: “tem que fazer várias maquetes ao mesmo tempo", "construir várias maquetes ao mesmo tempo" e "quando fica abandonada na escola", como se pode perceber, em relação ao último comentário, de fato os alunos ficam desapontados quando veem que, depois de pouco tempo, seus trabalhos são abandonados ou jogados fora.

O professor tem que estar atento a esse tipo de atitude e, quando for trabalhar com maquetes, precisa deixar claro que, caso nenhum aluno se importe, será enviado ao lixo ou, o que seria melhor, à coleta seletiva para reciclagem, surgindo daí uma boa maneira de o professor entrar num outro contexto e levar seus alunos até um local que realize a reciclagem do lixo.

Quanto aos intérpretes, estes acreditam que o docente precisa adquirir algumas posturas que torne o uso desse recurso melhor, como por exemplo: explicar aos alunos o "objetivo do uso da maquete", qual a "aplicação do método" e o "uso final da maquete".

Deve-se trabalhar essa metodologia, de acordo com os docentes entrevistados, "sem necessidade de se utilizar a escala", "de modo lúdico" e "deixando os alunos cria- 
rem o espaço de forma espontânea, para depois discutir o uso do espaço"; de forma que os alunos sintam prazer ao realizar o trabalho.

\section{MÚSICA}

A música sempre se fez presente na vida das pessoas, especialmente na dos jovens, sempre falando de algum assunto, ora do meio ambiente, ora censurando ações do governo. São infinitos os temas que a música consegue abordar, inclusive em relação à Geografia, mas essas mensagens podem passar despercebidas aos ouvidos das pessoas.

Curiosamente, os estudantes surdos também têm se beneficiado desse recurso; eles apontam sugestões de melhoria, tais como: "escolha da música, para que o intérprete possa traduzir mais facilmente”, " apresentar a letra da música” e, principalmente, "entonação dos sinais"; em relação a esse ultimo aspecto, é importante o intérprete mostrar aos surdos quando uma música possui um tom mais forte, quando as batidas possuem um som mais alto e quando a melodia é mais suave; assim esses educandos acreditam que podem entender a música um pouco melhor.

Os alunos ouvintes, em geral, gostam do uso da música em sala, pois ela está muito presente no cotidiano deles, porém alguns pontos precisam ser revistos pelos professores, como: "a escolha das músicas" e a "seleção de músicas e clipes"; mesmo sabendo que é difícil agradar a todos os gostos musicais de uma turma, o educador poderá tentar trazer para a sala músicas que muitas vezes retratam a realidade do estudante.

Os tradutores são receosos quanto ao uso dessa prática, pois muitas vezes eles não conseguem passar a música aos surdos da maneira mais fiel possível; tanto para eles quanto para os professores entrevistados, a forma como a tradução deve ser realizada deve ser corrigida. As respostas foram: "a prática de sinais", "a forma como se transmite ao aluno surdo tem que ser respeitada" e "aplicação do método deve ser mais direta"; as duas primeiras sugestões remetem à prática do intérprete, enquanto a terceira trata das melhorias que os docentes deverão fazer.

Os docentes também avaliam algumas posturas que podem ser corrigidas para melhorar o uso dessa técnica, tais como: "escolha das músicas”, "a abordagem que se faz da música", e "a qualidade do material"; essas são atitudes que os professores percebem que estão dificultando o uso desse recurso.

\section{SAÍDA DE CAMPO}

O trabalho de campo tem se mostrado um recurso eficiente para prender a atenção dos alunos. É uma ação que favorece a melhoria da relação dos alunos entre si e também com os professores. Além disso, o método faz com que os alunos assimilem e entendam melhor os conteúdos, podendo ajudar o aluno na transformação de condutas e no desenvolvimento da própria personalidade, o que o auxiliará na sua vida futura, tanto social como profissional. 
Os alunos surdos sugerem que o campo deve priorizar um "lugar com melhor acesso", pois dessa forma eles acreditam que poderiam aproveitar melhor essa aula.

Para os estudantes ouvintes esse tipo de aula pode ser aperfeiçoado caso o educador tome algumas posturas, tais como: "escolha do trajeto" e "a forma como se realiza essa aula"; é importante que os professores levem em consideração as opiniões dos alunos, para preparar suas aulas.

Em relação aos comentários dos tradutores acerca de como se pode melhorar a prática dessa metodologia, eles afirmam que deve ocorrer da seguinte forma: "a seleção do roteiro", "escolha de locais mais apropriados"; essas observações mostram que os educadores devem preparar o roteiro e conversar com os alunos sobre o que será feito em campo, antes mesmo de realizar a atividade, para que eles saibam o que será estudado em campo.

Os docentes sentem a necessidade de melhorar: "o roteiro", "seleção dos locais e abordagem em campo", e "otimizar o tempo no local"; essas melhorias visam estimular a vontade do aluno pela aula.

\section{DO USO LIVRO DIDÁTICO}

Constituindo-se em um apoio para as aulas, o livro didático não deve ser usado como método de ensino, mas como um subsídio ao professor. No ambiente acadêmico-profissional, inúmeras discussões priorizam o livro didático, tanto do ponto de vista metodológico como de conteúdo.

Em alguns debates o livro didático é considerado um dos poucos auxílios de que o professor, no Brasil, dispõe para a realização do seu trabalho. Na verdade, ele torna-se fonte única de informações para muitos, e em várias oportunidades, as informações nele contidas não são merecedoras de total credibilidade. Essa realidade persiste nas salas de aulas com alunos surdos e ouvintes.

O livro didático é visto como sendo uma obrigatoriedade imposta pelo governo de homogeneização da sociedade. As críticas que os professores fazem são referentes à falta de conteúdo das cartilhas que os governos aprovam e distribuem para serem utilizadas nas escolas. As poucas ilustrações, as falhas nas ofertas pedagógicas e as disparidades [?] existentes entre o projeto pedagógico da escola e o conteúdo dos livros adotados são os principais motivos das críticas.

Para ser adequado ao aluno, o livro didático deve apresentar os conteúdos e atividades partindo de ideias, noções e experiências que ele já possui, apreendidas através do senso comum no cotidiano vivido, respeitando sua fase cognitiva. Além disso, o livro deve apresentar estratégias de integração dos conhecimentos geográficos e das experiências que os alunos possam deter em relação aos novos conceitos elaborados. Por outro lado, os livros também devem contribuir no desenvolvimento progressivo da autonomia do aluno nos estudos, com uma abordagem em que ele seja tratado como sujeito ativo nos processos de ensino e de aprendizagem. Devem, ainda, estimular 
sua curiosidade para o aprendizado sistemático (científico), desenvolvendo, para esse fim, processos cognitivos básicos e níveis sucessivos de abstração. (SPÓSITO, 2006, p. 24).

Considerando-se somente os conteúdos geográficos, o problema torna-se ainda mais temeroso, já que as informações constadas nos livros são mínimas e a isso soma-se a pouca informação do professor, com resultado não satisfatório. Porém, constata-se que o professor das séries iniciais, de um modo abrangente, leciona Geografia tendo como sustentação apenas a narração dos fatos e quase sempre atrelado ao livro didático, e dessa maneira o ensino de Geografia apresenta dificuldades tanto de ordem epistemológica e de pressupostos teóricos como no que diz respeito à seleção dos conteúdos.

Uma solução possível de transformar essa situação é investir na qualificação do professor, pois ele conhece a realidade em que o seu aluno está envolvido e pode trabalhar a partir dela. Corrêa (2000, p. 12) afirma que os livros didáticos são:

[...] portadores de conteúdos reveladores de representações e valores predominantes num certo período de uma sociedade que, simultaneamente à historiografia da educação e da teoria da história, permitem rediscutir intenções e projetos de construção e de formação social.

Para Corrêa, é possível que componentes que melhor possam nos trazer indícios dos limites, pensamentos e abordagens colocados pelas matérias escolares, como parte das lógicas de um conteúdo curricular, sejam os livros escolares.

A Geografia pode e deve ajudar na formação desse aluno; observando, interpretando, descrevendo e analisando o mundo, colaborando para que o aluno possa desenvolver, desde as primeiras séries, uma leitura crítica da realidade social.

É de fundamental importância que as universidades, os profissionais da área do ensino e os estudiosos busquem adquirir experiências pedagógicas que incentivem a criatividade e a habilidade de percepção, de descrição, de experimentação e de síntese.

\section{CONSIDERAÇÕES FINAIS}

De um modo mais claro, pode-se afirmar que, além de uma modernização na forma de ensinar, a realização do conhecimento por meio de recursos diferenciados é uma ação que liga o aluno à realidade em que vive.

Diversificando a metodologia de ensino que será aplicada, o professor poderá reproduzir ensinamentos criativos e experiências que desenvolvam um poder de estimulação. O professor pode reavaliar sua prática de ensino sempre que achar preciso, e assim estará colaborando na formação de cidadãos mais críticos, que deverão encontrar no ensino a base para entender o espaço geográfico.

A experiência do professor [?] oferece a ele uma aproximação entre seu cotidiano como professor e o entendimento de que ensinar não significa somente transmitir assuntos e sim uma reciprocidade de conhecimentos que requer ética, cumplicidade, bom senso 
e muita pesquisa. Essa incessante procura por uma educação geográfica de qualidade possibilita a transformação da situação atual do aprendizado em algo maior e melhor para o desenvolvimento intelectual e pessoal dos alunos e do próprio professor.

O professor pode refletir constantemente sobre a consciência da dimensão política de sua ação, isto é, do seu papel social da sua profissão, buscando uma atitude idônea e procurando expandir sua visão sobre o mundo com clareza e profundidade, atitude própria para um ensino consistente e moderno".

Nessa direção o professor deverá ser capaz de coordenar a ação política do seu trabalho com a dimensão técnica e também a mediação entre essas duas situações por uma terceira, a dimensão ética, essencial para a fundamentação de uma prática competente.

Diante de tudo o que foi exposto espera-se que a educação escolar proporcione os subsídios suficientes para a organização de uma nova prática geográfica, sustentada numa metodologia de construção de saberes significativos, que possibilitem aos alunos se colocarem no âmbito social, considerando as relações e reproduções organizadas em seu espaço de vivência e/ou de sobrevivência.

Todas as metodologias apresentadas neste trabalho têm como principal objetivo estabelecer o ensino de Geografia para alunos surdos e alunos ouvintes, de modo que os mesmos obtenham conhecimento crítico da forma mais dinâmica possível, dando oportunidades de aprendizagem para os dois grupos. E, ainda, levam-se em consideração as propostas pedagógicas apresentadas nas Diretrizes Curriculares de Geografia para a Educação Básica do Paraná, de 2008.

Nota-se no Quadro 1 que não houve nenhum aspecto ruim ou péssimo para a aplicação desse método, sendo que, das 12 pessoas entrevistadas para cada prática de ensino (alunos surdos e alunos ouvintes, intérpretes e professores, sendo três de cada), todas classificaram o uso dessas práticas como regular, bom e excelente em determinados momentos.

Quadro 1 - Opinião dos entrevistados em relação às metodologias de ensino

\begin{tabular}{|c|c|c|c|c|c|}
\hline & \multicolumn{5}{|c|}{ OPINI ̃̃O DOS ENTREVISTADOS } \\
\hline ATIVIDADES PROPOSTAS & EXCELENTE & BOM & REGULAR & RUIM & PÉSSIMO \\
\hline Atividades lúdicas & 4 & 6 & 2 & 0 & 0 \\
\hline Charges, tiras e quadrinhos & 5 & 5 & 2 & 0 & 0 \\
\hline Desenhos & 1 & 6 & 5 & 0 & 0 \\
\hline Filmes e vídeos & 5 & 7 & 0 & 0 & 0 \\
\hline Globo terrestre & 0 & 5 & 7 & 0 & 0 \\
\hline Gráficos, quadros e tabelas & 0 & 6 & 6 & 0 & 0 \\
\hline Imagens e fotos & 6 & 6 & 0 & 0 & 0 \\
\hline Internet e computadores & 0 & 6 & 6 & 0 & 0 \\
\hline Jornais e revistas & 1 & 7 & 4 & 0 & 0 \\
\hline Literatura & 5 & 7 & 0 & 0 & 0 \\
\hline Mapas e atlas & 6 & 6 & 0 & 0 & 0 \\
\hline Maquetes & 5 & 7 & 0 & 0 & 0 \\
\hline Músicas & 1 & 8 & 3 & 0 & 0 \\
\hline Saída de campo & 2 & 8 & 2 & 0 & 0 \\
\hline
\end{tabular}

Fonte: Pesquisa realizada em campo, por meio de entrevistas com professores, intérpretes, alunos ouvintes e alunos surdos. FONSECA, R. L. (Org.). 
Esses questionamentos mostram, no entanto, que alguns pontos precisam ser averiguados para que haja o aperfeiçoamento dessas técnicas, com a finalidade de melhor ensinar os educandos envolvidos. Trata-sede atitudes por parte dos educadores que podem fazer os estudantes se dedicarem e se interessarem mais ou menos pela Geografia. $\mathrm{O}$ educador deve, ainda, procurar, por meio dos conteúdos estudados, aprofundar o conhecimento crítico e os aspectos cognitivos em cada aluno.

À escola cabe averiguar determinadas sugestões apresentadas pelos alunos surdos e ouvintes, tradutores e professores, como forma de promover melhor acesso aos materiais e recursos necessários, além de respaldar toda e qualquer ação pedagógica que possa aprimorar a qualidade do ensino que a instituição oferece à comunidade escolar.

\section{REFERÊNCIAS}

CALLAI, H. C. A Geografia e a escola: muda a geografia? Muda o ensino? In: Terra Livre, n. 16 (Paradigmas da Geografia, Parte I). São Paulo: AGB, $1^{\circ}$ semestre 2001. p. 133-152.

CASSETI, V. A natureza e o espaço geográfico. In: MENDONÇA, F.; KOZEL, S. (Orgs.) Elementos de epistemologia da geografia contemporânea. Curitiba: Ed. da UFPR, 2002. p. 145-163.

CORREAA, R. L. T. O livro escolar como fonte de pesquisa em História da Educação. Caderno Cedes, ano XX, n. 52, 2000. p. 11-23.

PARANÁ. Diretrizes Curriculares de Geografia para a Educação Básica. Secretaria de Estado da Educação. Curitiba, 2008.

SPÓSITO, E. S. Livro didático em geografia, do processo de avaliação à sua escolha. In: PAVÃO, A. C. (Org.). O livro didático em questão. 2006, p. 26-37. Disponível em: <http://tvbrasil.org.br/fotos/salto/ series/161240LivroDidatico.pdf>. Acesso em: 17 set. 2011.

Recebido em 09/10/2012

Aceito para publicação em 22/10/2013 